\title{
PHARMACOGNOSTIC INVESTIGATION OF GALANTHUS WORONOWII LOSINSK. AND GALANTHUS NIVALIS L. HERBAL PHARMACEUTICAL SUBSTANCES (MICROSCOPIC AND MACROSCOPIC ANALYSIS)
}

\author{
DMITRY OLEGOVICH BOKOV ${ }^{1,2 *}$ \\ ${ }^{1}$ Department of Pharmaceutical and Natural Sciences, Sechenov First Moscow State Medical University, 8, Trubetskaya st., Moscow, \\ 119991, Russia. ${ }^{2}$ Department of Laboratory of Food Chemistry, Federal Research Center for Nutrition, Biotechnology and Food Safety, \\ 2/14, Ustyinsky pr., Moscow, 109240, Russia. Email: fmmsu@mail.ru
}

Received: 27 April 2018, Revised and Accepted: 14 June 2018

\section{ABSTRACT}

Objective: Today drug produced from snowdrop species (Galanthus woronowii Losinsk. and Galanthus nivalis L.) used in Russian traditional medicine for nervous and cardiovascular systems disorders treatment.Pharmacognostic study of fresh snowdrop plants including macroscopic and microscopic (morpho-anatomical diagnostic features) evaluation for identification of herbal pharmaceutical substances (HPS).

Methods: Macro- and micro-scopic evaluation was carried out according to general pharmacopeial monographs of State Pharmacopoeia of Russian Federation XIII ed., Photographs were obtained by the microscope "Altami 139T" (10× eyepiece and lenses: 4×, 10×, 40×, 100×) with a digital camera eyepiece UCMOS05100KPA; images were processed using Altami Studio program.

Results: In a pharmacognostic study of G. nivalis and G. woronowii HPS linear dimensions were determined. Several microscopic diagnostics and anatomical signs of snowdrops were investigated: Adaxial and abaxial leaf epidermis; epidermis of corolla, peduncle; internal and external outer scale epidermis, internal and external storage scale epidermis, and sizes of cells and cellular inclusions (starch grains and calcium oxalate raphides). G. woronowii and G. nivalis HPS possess differences both in the micro and macro levels in the linear dimensions. In general, dimensions of G. nivalis organs are much smaller than $G$. woronowii ones, this aspect is also expressed in the cell structures linear dimensions. The complex of macro- and micro- diagnostic signs allows to identify the snowdrop species.

Conclusion: The results of the investigation can be used in routine quality control and for inclusion of pharmacopeial monographs for snowdrop HPSs.

Keywords: Galanthus woronowii, Galanthus nivalis, Herbal pharmaceutical substances.

(c) 2018 The Authors. Published by Innovare Academic Sciences Pvt Ltd. This is an open access article under the CC BY license (http://creativecommons. org/licenses/by/4. 0/) DOI: http://dx.doi.org/10.22159/ajpcr.2018.v11i10.26957

\section{INTRODUCTION}

The Amaryllidaceae family consists of about 85 genera and 1100 species. These plants are distributed throughout the warm temperate and tropical regions of the world [1]. It's well aware that the genus Galanthus numbers 19 species, six varieties, and two natural interspecies hybrids (World Cheklist of Selected Plant Families) [2]. Galanthus woronowii Losinsk. (Woronowii snowdrop) and Galanthus nivalis L. (common snowdrop) are an early-spring flowering bulbous plant species cultivated for its ornamental qualities in gardens and found application in medicine. Herbal pharmaceutical substances (HPS), prepared from plants of the genus Galanthus L., contain several biologically active compounds: Amaryllidaceae alkaloids [35], flavonoids, organic, and hydroxycinnamic acids [6]. Alkaloids are biologically active substances that posse strong pharmacological activities of medicinal plants $[7,8]$. Mother tinctures produced from both Galanthus species are used in the preparation of homeopathic drugs [9]. Macro- and micro-scopic determinations of diagnostic features in HPS are very important stage of pharmacognostic analysis (herbs, fruits, leafs, etc.) [10-15].

The aim of this research is a pharmacognostic study of fresh snowdrop plants including macroscopic and microscopic (morpho-anatomical diagnostic features) evaluation for identification of HPS.

\section{METHODS}

The plants were collected at blooming period at the Botanical Garden in Sechenov University in April 2017. The whole plants (HPS) - aerial parts (flowers and leaves) and the bulbs with roots - of $G$. woronowii and G. nivalis were used for pharmacognostic analysis.

Macro- and micro-scopic evaluations were carried out according to general pharmacopeial monograph of State Pharmacopoeia of Russian Federation XIII ed., Vol. 2 "The root, rhizome, bulb, tuber, corm;" "Herbs;" "Method of microscopic and microchemical studies of medicinal plants and medicinal plant preparations" [16]. Photographs were obtained by the microscope "Altami 139T" (10× eyepiece and lenses: 4×, 10×, 40×, $100 \times$ ) with a digital camera eyepiece UCMOS05100KPA; images were processed using Altami Studio program.

\section{RESULTS AND DISCUSSION}

\section{Macroscopic evaluation of Galanthus HPS}

Macroscopic evaluation of $G$. woronowii

The G. woronowii HPS is presented at Fig. $1 \mathrm{a}$. The bulb is pyriform, $3.0 \mathrm{~cm}$ in length, $2.5 \mathrm{~cm}$ in diameter. The outer surface is slightly wrinkled, covered with yellow-brown leathery scales. The outer bulb scales are arranged in step order. Bulb's color after covering scales removal is white. The roots are cylindrical, threadlike, $25 \mathrm{~cm}$ in length, and $2 \mathrm{~mm}$ in diameter, white. Leaves are simple, broadly, pointed, bright green with a yellowish tinge and have glabrous shiny surface, characteristic lenticels, and two undeveloped longitudinal folds. Leaves without stem have the keel on the lower surface, tapering at the base and gradually turning into a long sheath. The leaf sheath is $3.5-6.0 \mathrm{~cm}$ in length, leaf is $1.5-2.5 \mathrm{~cm}$ in wide, and $15-23 \mathrm{~cm}$ in length. In a bud, one leaf covers another. Wax coating of the leaves is absent. The edge of leaf is entire; venation is 
parallel. Peduncle is cylindrical, ribbed, glabrous, $9-15 \mathrm{~cm}$ in length, $2.5 \mathrm{~mm}$ thick, and green. Flower is solitary, dialypetalous, hermaphrodite, has a white corolla perianth. Bract is linear, membranous, up to $4 \mathrm{~cm}$ in length, pedicels are $4.5 \mathrm{~cm}$ in length, 3 outer tepals are obovate, slightly curved $2.3 \mathrm{~cm}$ in length, $1.3 \mathrm{~cm}$ in wide; 3 inner tepals are $0.8 \mathrm{~cm}$ in wide, $1.2 \mathrm{~cm}$ in length, tapering downward wedge, flat, erect, with a notch and large $1.6 \mathrm{~mm}$ horseshoe-shaped green spot at the top. 6 stamens are $0.6 \mathrm{~cm}$ in length, have short filaments that are attached to the base of the perianth; anthers have a cusps; ovary is lower, oblong, $0.3-0.4 \mathrm{~cm}$ in length, has three locules. Stile is thread-like, has acute stigma. The HPS smell is specific, weak; the taste is not determined (toxic HPS).

\section{Macroscopic evaluation of Galanthus nivalis}

The G. nivalis HPS is presented at Fig. 1b. The bulb is pyriform or conical, $2.0 \mathrm{~cm}$ in length, and $1.5 \mathrm{~cm}$ in diameter. The outer surface is slightly wrinkled, covered with light-brown leathery scales. The outer bulb scales are arranged at the same level. Bulb's color after the covering scales removal is white. The roots are cylindrical, thin, filamentous $15 \mathrm{~cm}$ in length, $1 \mathrm{~mm}$ in diameter, white. Leaves are simple, linear, dark green or gray, glabrous, with a wax coating, on the tip are obtuse, at the base are slightly tapered and gradually turning into a long sheath, and in the bud are flatly adjacent to each other. The edge of the leaf is entire; venation is parallel. The leaf sheath is $2.0-4.0 \mathrm{~cm}$ in length, leaf is $8-12 \mathrm{~cm}$ in length, $0.4-0.5 \mathrm{~cm}$ in wide. Peduncle is slightly ribbed, cylindrical, glabrous, $7-10 \mathrm{~cm}$ in length, $1.5 \mathrm{~mm}$ thick, green. Flower is solitary, dialypetalous, hermaphrodite, has a white corolla perianth. Bract is linear, membranous, up to $2 \mathrm{~cm}$ in length, pedicels are $2.5 \mathrm{~cm}$ in length, 3 outer tepals are oblong-obovate, $1.8 \mathrm{~cm}$ in length, $0.6 \mathrm{~cm}$ in wide; 3 internal tepals are $1.0 \mathrm{~cm}$ in length, $0.4 \mathrm{~cm}$ in wide, wedge-shaped, flat, with notch and large $1 \mathrm{~mm}$ horseshoe-shaped green spot at the top. 6 stamens are $0.5 \mathrm{~cm}$ in length, have short filaments that are attached to the base of the perianth; anthers have cusps; ovary is lower, oblong, $0.1-0.2 \mathrm{~cm}$ in length, has three locules. Stile is thread-like, has acute stigma. The HPS smell is specific, weak; the taste is not determined (toxic HPS).

\section{Microscopic evaluation of Galanthus HPS}

\section{Microscopy of Galanthus leaf}

G. woronowii lamina is dorsoventral, triangular at the base, has long edges, which are bent inward, leaf width is $3.6-4.2 \mathrm{~mm}$, the number of conducting bundles is 28-31 (Fig. 2a). G nivalis lamina is dorsoventral and has the shape of a concave triangle with short edges at the base. Leaf width is 2.4$3.1 \mathrm{~mm}$, the number of conducting bundles is 12-20 (Fig. 2b).

At both sides of Galanthus leaf (Figs. 3 and 4), the epidermis cells are elongated, rectangular with straight walls. The epidermis cell walls have beaded thickening. The stomata are round, surrounded by 4 (rarely 5) epidermal cells (tetra- and penta-cytic types). Cuticle is smooth, sometimes wrinkled longitudinally. Leaf mesophyll is not clearly differentiated into palisade and also spongy tissue, consisting of round cells. Several mesophyll cells rows, adjacent to the upper epidermis, consist of slightly radially elongated cells. In the central part, mesophyll has loose structure, thereby forming large air cells which are disposed between the conducting bundles. In the peripheral part of mesophyll, there are cells containing calcium oxalate raphides bundles (Fig. 5). Conducting bundles type of side and central ribs is collateral. Fiber vascular bundles include netted and ladder-shaped vessels and spiral tracheids.

\section{Microscopy of Galanthus flower}

At both sides, the corolla epidermis consists of isodiametric wing cells with papillate projections (Fig. 6). Papillate projections of abaxial epidermis are developed better. Cuticle is longitudinally wrinkled. Stomata are absent. Pollen grains are oval, monocolpate, and heteropolar with a glabrous surface (Fig. 7).

The peduncle epidermis cells are rectangular; the walls are straight, the cuticle is smooth (Fig. 8). Stomata type is tetracytic; size is similar to leaf stomata. In the peripheral part of the peduncle mesophyll, there are cells containing calcium oxalate raphides.

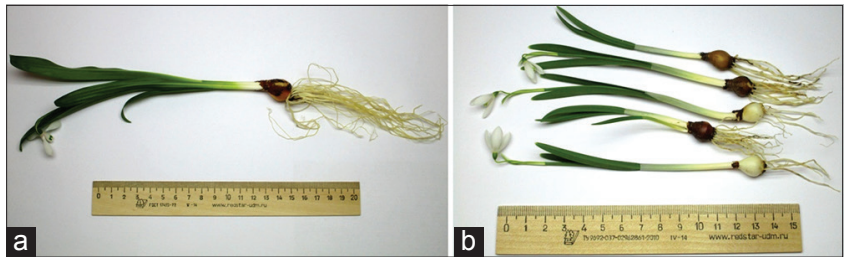

Fig. 1: Appearance of Galanthus woronowii herbal pharmaceutical substances (a); Galanthus nivalis herbal pharmaceutical substances (b)

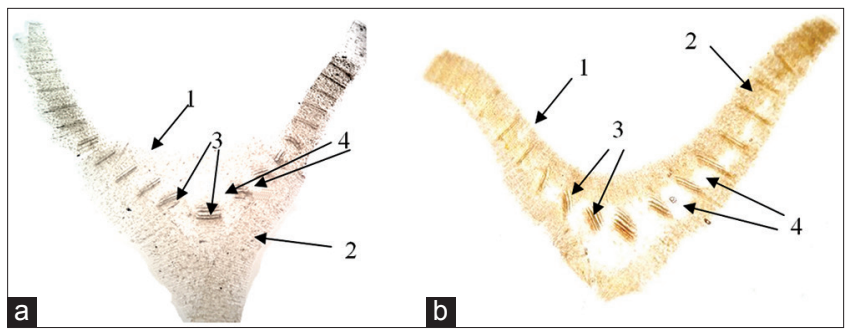

Fig. 2: Cross section of Galanthus woronowii leaf (a); Galanthus nivalis leaf (b) ( $\times 40)$. (1) epidermis, (2) mesophyll, (3) conducting bundles, (4) air cells

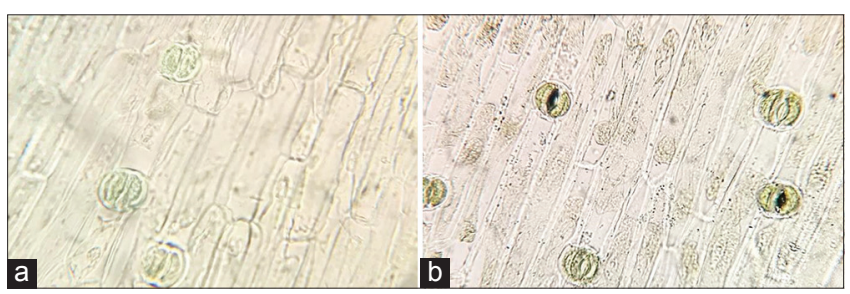

Fig. 3: Adaxial epidermis of Galanthus woronowii leaf (a); Galanthus nivalis leaf (b) $(\times 400)$

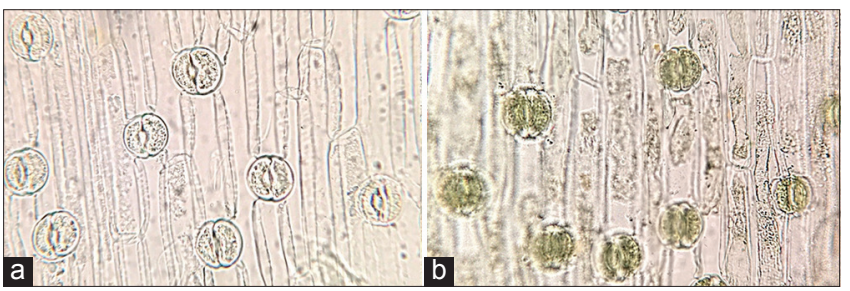

Fig. 4: Abaxial epidermis of Galanthus woronowii leaf (a); Galanthus nivalis leaf $(\mathrm{b})(\times 400)$

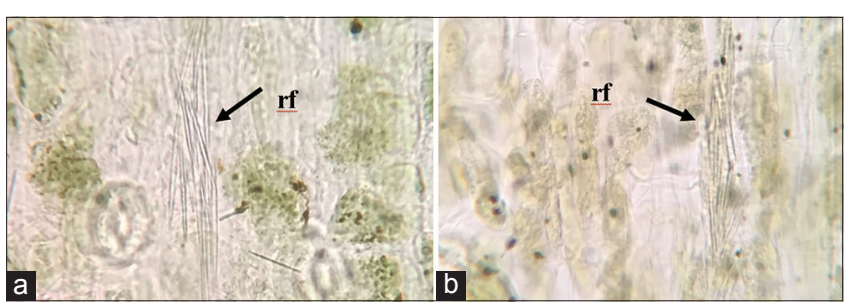

Fig. 5: Calcium oxalate raphides (rf) in mesophyll cells of Galanthus woronowii leaf (a); Galanthus nivalis leaf (b) $(\times 400)$

\section{Microscopy of Galanthus bulb}

The outer scales are dead shell with completely deformed parenchyma cells. External and internal outer scale epidermis is composed of prosenchymatous cells with rounded corners and beaded thickening (Figs. 9 and 10). 


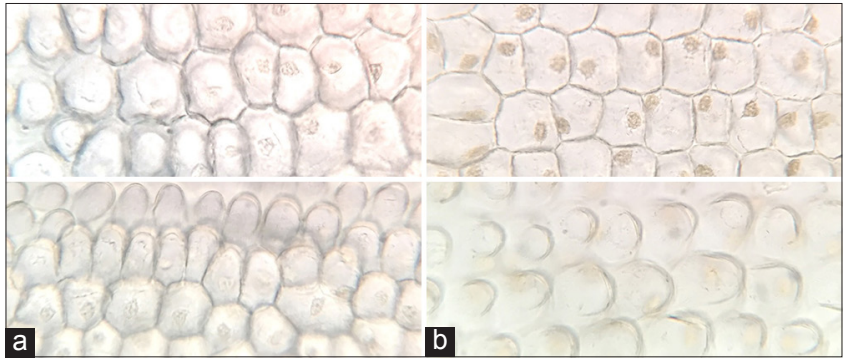

Fig. 6: Enidermis cells of Galanthus woronowii corolla

(a); Galanthushivalis (b) corolla. (1) Isodiametric, wing cells; (2) papillate projections $(\times 400)$

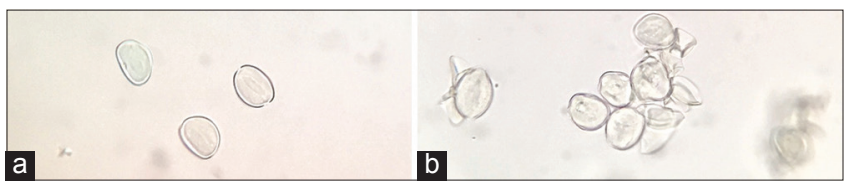

Fig. 7: Pollen grains of Galanthus woronowii (a); Galanthus nivalis (b) $(\times 400)$

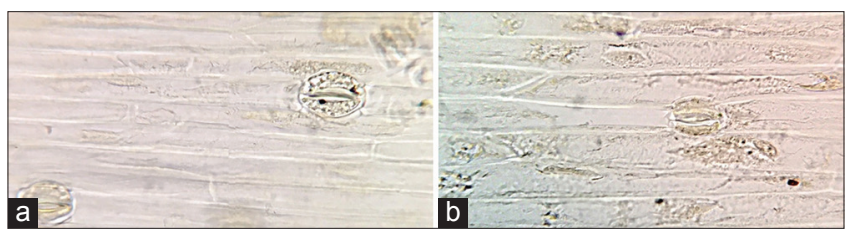

Fig. 8: Peduncle epidermis of Galanthus woronowii (a); Galanthus nivalis $(\mathrm{b})(\times 400)$

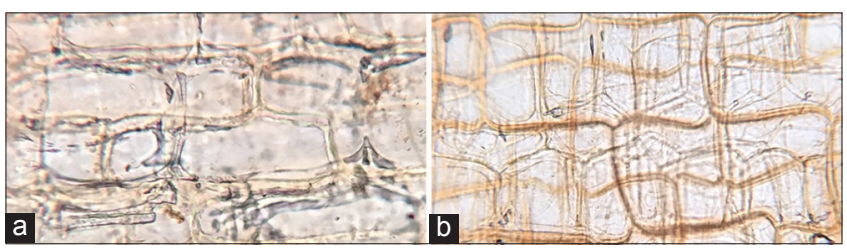

Fig. 9: External epidermis of Galanthus woronowii (a) and Galanthus nivalis (b) outer scale $(\times 400)$

Storage scales structure is similar to the leaf. External and internal epidermis of these scales consists of oval cells that are slightly elongated in the tangential direction or isodiametric (Figs. 11 and 12)

Ground tissue consists of thin-walled round-shaped cells filled with rounded-ovate starch grains (Fig. 13). Large starch grains have 2-3, rarely 4 radial cracks (Fig. 14). Raphides are contained in the outer part of scales ground tissue and are arranged in bundles, parallel to the longitudinal axis of the bulb. Conducting bundles type is closed collateral, they are located closer to the inner side of the scales, and they have parenchymal lining.

Comparison of microscopic G. woronowii and G. nivalis features is presented in Table 1.

Nevertheless, plants of $G$. woronowii and G. nivalis are not pharmacopeial HPS, and as a consequence, there are no standardization approaches to its quality control. Although several research papers for botanical evaluation of Galanthus species were published, there are no systematic data for standardization of HPS [17-21]. We have conducted the first study in pharmacognostic aspect. Obtained data will be used in creating documentation regulating the quality of Galanthus HPS.

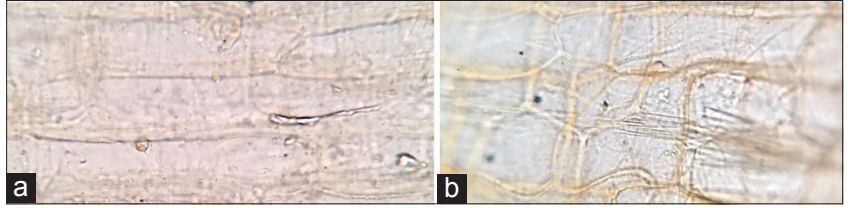

Fig. 10: Internal epidermis of Galanthus woronowii (a) and Galanthus nivalis (b) outer scale $(\times 400)$

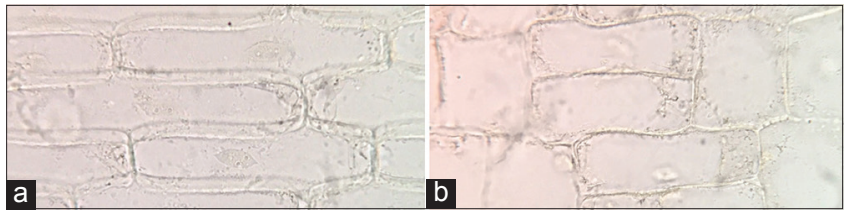

Fig. 11: External epidermis of Galanthus woronowii storage scale (a); Galanthus nivalis $(b)$ storage scale $(\times 400)$

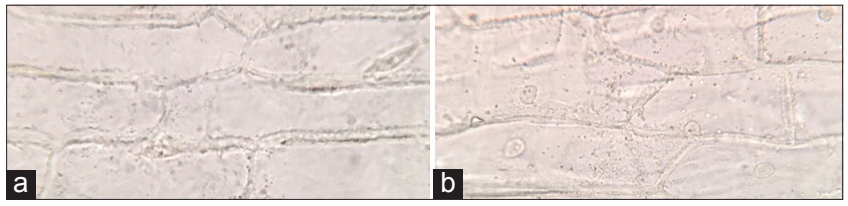

Fig. 12: Internal epidermis of Galanthus woronowii storage scale (a); Galanthus nivalis $($ b) storage scale $(\times 400)$

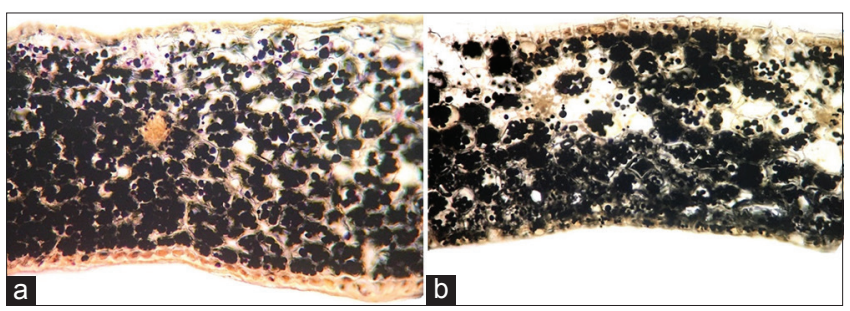

Fig. 13: Cross-section of Galanthus woronowii storage scale (a); Galanthus nivalis (b) storage scale, Lugol solution staining $(\times 400)$

\section{CONCLUSION}

In summary, during pharmacognostic research macroscopic and microscopic (morpho-anatomical diagnostic features) evaluation for identification of $G$. woronowii and G. nivalis HPS were carried out, linear dimensions of plant organs were determined.

As the result of this study Galanthus herbal pharmaceutical substances (HPS), linear dimensions were determined. Several microscopic diagnostics and anatomical signs of snowdrops were investigated: Adaxial and abaxial leaf epidermis; epidermis of corolla, peduncle; internal and external outer scale epidermis, internal and external storage scale epidermis, size of cells and cellular inclusions (starch grains and calcium oxalate raphides). It has been established that $G$. woronowii, $G$. nivalis HPS possess differences both in the micro and in the macro levels in the linear dimensions. In general, dimensions of G. nivalis organs are much smaller than $G$. woronowii ones, this aspect is also expressed in the cell structures linear dimensions. Thus, complex of macro- and microdiagnostic signs allows to identify the snowdrop species.

\section{ACKNOWLEDGMENT}

I would like to thank professor, corresponding member of Russian Academy of Sciences Irina Aleksandrovna Samylina, for her useful communications and constant help.

\section{AUTHOR'S CONTRIBUTIONS}

I declare that this work was done by the author named in this article. 
Table 1: Comparison of microscopic Galanthus woronowii, Galanthus nivalis features

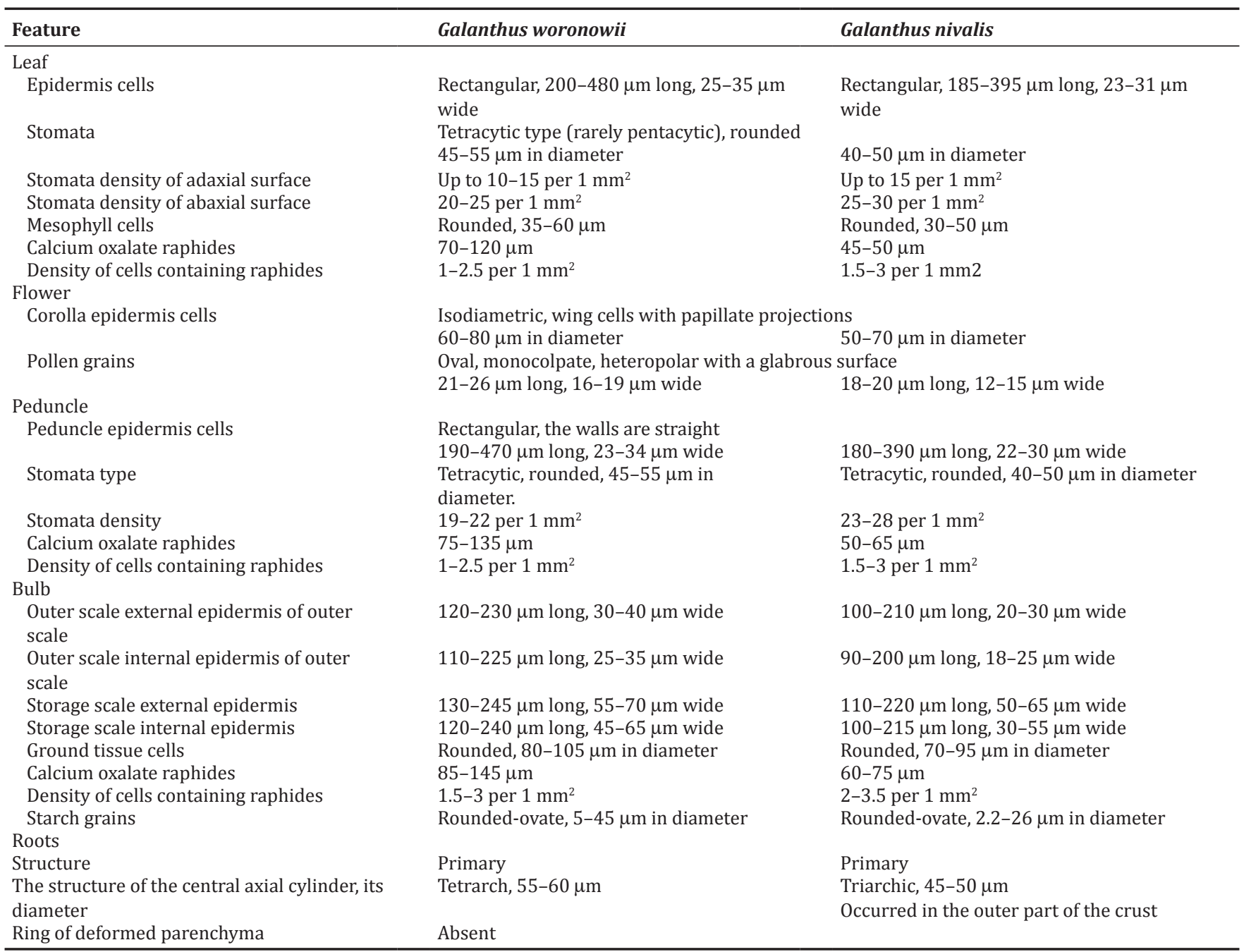

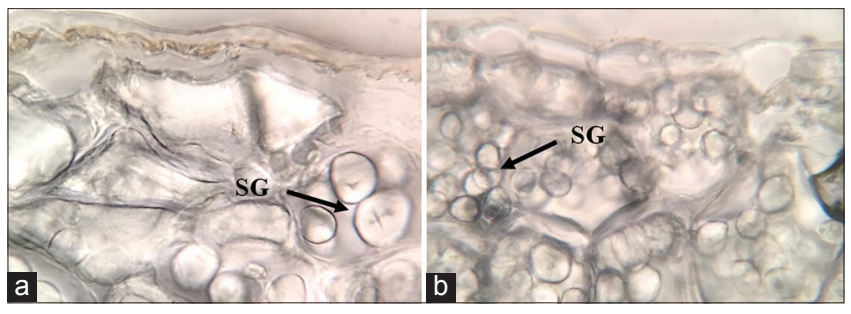

Fig. 14: Ground tissue cells of Galanthus woronowii storage scale (a); Galanthus nivalis (b) storage scale with starch grains (SG) $(\times 400)$

\section{CONFLICTS OF INTEREST}

The author had no conflicts of interest.

\section{REFERENCES}

1. Willis JC. Amaryllidaceae. A Dictionary of the Flowering Plants and Ferns. $8^{\text {th }}$ ed. Cambridge: Cambridge University Press; 1988.

2. World Checklist of Selected Plant Families (WCSP). Royal Botanic Gardens, Kew. Available from: http://apps.kew.org/wcsp/home.do. [Last cited on 2018 April 25].

3. Bokov DO, Samylina IA, Malinkin AD, Nikolov S. Application of HILIC-UV method in analysis of medicines containing Amaryllidaceae alkaloids. Russ J Biopharm 2017;9:52-8.

4. Sarikaya BB, Kaya GI, Onur MA, Bastida J, Somer NU. Phytochemical investigation of Galanthus woronowii. Biochem Syst Ecol
2013:51:276-9.

5. Berkov S, Codina C, Viladomat F, Bastida J. Alkaloids from Galanthus nivalis. Phytochemistry 2007;68:1791-8.

6. Bokov DO, Malinkin AD, Samylina IA, Bessonov VV. Hydroxycinnamic and organic acids of snowdrops (Galanthus L.). J Appl Pharm Sci 2017;7:36-40

7. Prakasia PP, Nair AS. Evaluation of in vitro antioxidant potential of the total crude alkaloid extract of Glycosmis pentaphylla (Retz.) Correa leaves. Int J Pharm Pharm Sci 2016;8:85-91.

8. Debnath B., Uddin MD J, Patari P, Das M, Maiti D, Manna K. Estimation of alkaloids and phenolics of five edible cucurbitaceous plants and their antibacterial activity. Int J Pharm Pharm Sci 2015;7:223-7.

9. Boericke W. Homeophatic Materia Medica. New York: Kessinger Publishing; 2004.

10. Yanala SR, Sathyanarayana D. Powder microscopic studies of the fruits of tribulus terrestris linn collected from different geographical locations of South India-a comparative stdy. Int J Pharm Pharm Sci 2017;9:158-64.

11. Saini S, Dhiman A, Nanda S. Pharmacognostical and phytochemical studies of Piper betle Linn. Leaf. Int J Pharm Pharm Sci 2016;8:222-6.

12. Sharmila S, Kalaichelvi K, Dhivya SM. Pharmacognostic standardisation of Cayratia pedata (Lam.) Gagnep var glabra gamblean endemic and endangered medicinal climber in Thiashola, Nilgiris. Int J Pharm Pharm Sci 2017;9:57-63.

13. Ali I, Rizwani GH, Shareef H, Khan S. Pharmacognostic studies of Dalbergia sisso Roxb. Int J Pharm Pharm Sci 2016;8:48-53.

14. Ramamoorthy SK, Manickam D, Subramaniam S, Subramaniam S. Standardisation and phytochemical screening of traditional formulation. Int J Curr Pharm Res 2017;9:70-4.

15. Kaur M, Yadav R. Pharmacognostic, ethnopharmacological, 
phytochemical and pharmacological profile of wild guava I.E. Careya arborearoxb. Int J Curr Pharm Res 2017;9:1-7.

16. State Pharmacopoeia of the Russian Federation. $12^{\text {th }}$ ed, Vol. 2. Available from: http://www.193.232.7.107/feml. [Last cited on 2018 April 25].

17. Davis AP, Barnett JR. The leaf anatomy of the genus Galanthus L. (Amaryllidaceae J. St.-Hil.). Bot J Linn Soc 1997;123:333-52.

18. Sahin NF. Morphological anatomical and physiological studies on Galanthus ikariae Baker and G. rizehensis Stern (Amaryllidaceae) grown around NE Turkey. Pak J Bot 1998;30:117-31.

19. Chudzik B, Snieżko R, Szaub J. Biology of flowering of Galanthus nivalis L. (Amaryllidaceae). Ann Univ Mariae Curie-Skłodowska EEE Hortic 2002;10:1-10.

20. Budnikov G. Morphological variation of specimens and populations of Galanthus nivalis L. in Western regions of Ukraine. Thaiszia J Bot Košice 2011;21:95-109.

21. Dönmez EO, IşIK S. Pollen morphology of Turkish Amaryllidaceae, Ixioliriaceae and Iridaceae. Grana 2008;47:15-38. 